Aletria, Belo Horizonte, v. 31, n. 2, p. 203-222, 2021

\title{
As ficções editoriais e narrativas de Robinson Crusoé
}

\section{Robinson Crusoe's Editorial and Narrative Fictions}

\author{
Lainister de Oliveira Esteves \\ Universidade Federal de Uberlândia (UFU), Uberlândia, Minas Gerais / Brasil \\ lainister.esteves@gmail.com \\ http://orcid.org/0000-0001-9912-0974
}

Resumo: Este artigo analisa os artifícios narrativos que caracterizam a trama de Robinson Crusoé, romance publicado em 1719 e considerado um dos textos fundadores da ficção moderna. O exame das estratégias de dissimulação da autoria, que considera a recepção setecentista das três obras relacionadas ao personagem, permite investigar as relações entre narração e ficcionalidade nos textos escritos por Daniel Defoe. A análise destes elementos constitutivos do romance como gênero letrado relacionado ao livro sugere uma história da literatura interessada nos efeitos produzidos pelos dispositivos editoriais e nas diferentes estratégias de atribuição de sentido potencializadas pela ampliação do escopo da crítica a partir do século XVIII.

Palavras-chave: ficção; narração; Robinson Crusoé.

Abstract: This article analyzes the narrative devices that characterize the plot of Robinson Crusoe, a novel published in 1719 and considered one of the founding texts of modern fiction. The examination of the strategies of authorship dissimulation, which considers the 18th century reception of the three works related to the character, allows to investigate the relations between narration and fictionality in the texts written by Daniel Defoe. The analysis of these constitutive elements of the novel as a literary genre related to books suggests a history of literature interested in the effects produced by editorial devices and in the different strategies of meaning attribution enhanced by the broadening of the scope of criticism from the 18th century on.

Keywords: fiction; narration; Robinson Crusoe. 
Robinson Crusoé é frequentemente considerado um dos textos fundadores da literatura moderna, isso porque a primeira obra ficcional de Daniel Defoe, publicada em 1719 e listada entre os maiores sucessos comerciais das letras do século XVIII, teve papel destacado na formação do sistema literário cuja economia combina registro autoral, técnica de representação, crítica e comércio. Associada à formatação do romance como gênero, a publicação também ajudou a consolidar a função de escritor como profissional do mercado das letras.

A importância da obra pode ser observada na diversidade de interpretações que caracterizam a história de sua recepção. Como lembra Thomas Kelner (2007), Robinson Crusoé foi lido de formas distintas: como metáfora da ascensão do individualismo; arquétipo do homo economicus; parábola religiosa; expressão da secularidade iluminista; e profecia da expansão colonial britânica, por exemplo. Nos mais de trezentos anos de debates em torno do texto, as diferentes leituras transformaram o livro de aventuras em fábula sobre a solidão; dramatização do declínio da cosmovisão cristã; além de relato da expansão comercial nas origens do capitalismo. As análises, que se confundem com os lugares-comuns que subsidiaram representações recorrentes da modernidade ocidental, evidenciaram a centralidade da problemática do realismo nos estudos sobre a historicidade do romance.

A conhecida definição de "realismo formal" formulada por Ian Watt (2010) em $A$ ascensão do romance afirma que o surgimento do romance no século XVIII caracteriza-se, entre outros fatores, pelo uso sistemático das funções referenciais da linguagem, base da formulação de convenções narrativas próprias do gênero. Essas convenções subsidiam a ideia do romance como retrato da experiência cotidiana e como privilégio da particularidade concreta, pois, segundo Watt (2010), é a singularidade de cenas e personagens o que garante a verossimilhança como efeito da maquinaria romanesca. Ainda de acordo com o crítico, Daniel Defoe teria sido o primeiro escritor inglês capaz de narrar as peculiaridades de um ambiente físico real (WATT, 2010). Ele destaca, por exemplo, como a ilha de Crusoé é representada a partir da descrição dos objetos ordinários que nela se encontram (WATT, 2010).

A trajetória crítica de Robinson Crusoé - do sucesso no século XVIII às inúmeras reedições e apropriações ocorridas nos séculos posteriores - perfaz um enredo de reorientações e deslocamentos estilísticos desenvolvidos no fluxo histórico das práticas literárias na 
qual a trama do naufrágio e da solidão insular reverbera o deslocamento semântico discursivo que transformou o romance no ponto de referência de um novo modelo de representação da realidade no qual a autoria sustenta a narração e o engenho ficcional produz os termos da sua referencialidade.

The Life and Adventures of Robinson Crusoe, publicado em 25 de abril de 1719, teve seis edições nos quatro meses seguintes. Editado por William Taylor, o livro teve tiragem de mil exemplares em cada edição, com considerável sucesso comercial (RODGERS, 1995). A sequência, The Farther Adventures of Robinson Crusoe, foi publicada em agosto do mesmo ano, enquanto Serious reflections during the Life and Surprising Adventures of Robinson Crusoe, terceira obra associada ao universo do personagem, veio a público em 1720. O conjunto não configura exatamente uma trilogia, pois apenas os dois primeiros livros são ligados pela mesma trama. O terceiro é uma reunião de ensaios sobre as implicações morais das aventuras narradas nos volumes anteriores.

São amplamente conhecidas as semelhanças entre a história de Robinson Crusoé e a situação vivida pelo marinheiro escocês Alexander Selkirk, que retornou à Inglaterra em 1711 após passar quatro anos e meio isolado em uma ilha na costa do Chile. A aventura foi reportada por Richard Steele, que publicou entrevista com Selkirk no periódico The Englishman. A evidente referência ao texto jornalístico, bastante discutida pela crítica é, no entanto, apenas um dos elementos narrativos que estruturam a ficcionalidade do primeiro romance de Daniel Defoe e que podem ser percebidos no título:

A vida e as estranhas e surpreendentes aventuras de Robinson Crusoé, De York, Marujo: que viveu vinte e oito anos sozinho numa ilha deserta na costa da América, perto da embocadura do grande rio Orinoco; tendo sido lançado à costa por um naufrágio, no qual morreram todos os homens menos ele. Com relato de como foi, afinal, estranhamente salvo por piratas. Escrito pelo próprio. (DEFOE, 2011, p. 41). ${ }^{1}$

\footnotetext{
1 "The Life and Strange Surprizing Adventures of Robinson Crusoe, Of York, Mariner: Who lived Eight and Twenty Years, all alone in an un-inhabited Island on the Coast of America, near the Mouth of the Great River of Oroonoque; Having been cast on Shore by Shipwreck, wherein all the Men perished but himself. With an Account of how he was at last as strangely deliver'd by Pyrates. Written by Himself." (DEFOE, 2007 , p. 42, grifo do autor).
} 
O título longo - adequado às convenções como observado em obras como Dom Quixote de La Mancha, de Miguel de Cervantes, Les Aventures de Télémaque, de François Fénelon - registra breve sinopse da trama e atesta a autoria como relato do protagonista. O leitor é sugestionado a acreditar se tratar de um registro autobiográfico.

Kevin Seidel (2011) considera improvável que Daniel Defoe tenha planejado de fato esconder a autoria do texto, e destaca que a artimanha foi rapidamente detectada pelos leitores ingleses. A pronta associação dos nomes de Daniel Defoe e Robinson Crusoé nos círculos letrados da época sugere que o uso do pseudônimo não serviu à efetiva ocultação da autoria.

No entanto, a reincidência da assinatura de Robinson Crusoé nos livros posteriores indica que a ficção de autor compõe estratégia narrativa que faz da autoria parte do enredo da obra. A análise da recepção da época aponta ainda que a dissimulação produziu efeitos na repercussão do texto, pois a relação entre relato e ficção sugeria um programa de leitura. O prefácio do primeiro livro dá prosseguimento à trama:

Se jamais a história das aventuras no mundo de algum homem em particular já mereceu vir a público, e foi digna de publicação, o editor do presente relato pensa ser este o caso. As maravilhas da vida desse homem excedem tudo que (a seu ver) se pode encontrar: mal se imagina que a vida de um homem seja capaz de maior variedade. A história é relatada com modéstia, com seriedade e uma aplicação religiosa dos acontecimentos aos usos que os sábios sempre lhes dão, a saber: a instrução de outros à luz deste exemplo, e para justificar e honrar a sabedoria da Providência em toda a variedade de nossas circunstâncias, aconteçam de modo que for. O editor julga que o relato seja uma história fiel; nem existe nela qualquer aparência de ficção. E no entanto pensa, posto que todas as coisas deste tipo costumam ser lidas às pressas, que o que ela pode trazer tanto em matéria de diversão quanto de instrução para o leitor será da mesma monta; e assim, acredita ele sem mais saudações ao mundo, ele lhes presta um grande serviço com a presente publicação. (DEFOE, 2011, p. 43). ${ }^{2}$

2 "If ever the Story of any private Man's Adventures in the World were worth making Publick, and were acceptable when Publish'd, the Editor of this Account thinks this will be so. The Wonders of this Man's Life exceed all that (he thinks) is to be found extant;* the Life of one Man being scarce capable of a greater Variety. The Story is told with Modesty, with Seriousness, and with a religious Application of Events to the 
O editor, suposto autor do prefácio, garante a veracidade da narrativa que revela ao mundo as maravilhas da vida do personagem singular. A trama começa com a negação de qualquer invenção, a história é digna de vir a público por ser extraordinária, e sobretudo, verdadeira. Se o título atesta que a narrativa foi escrita pelo protagonista, o prefácio reafirma o pacto entre autor, editor e público.

O mesmo prefácio faz referência a regras de composição poética como elementos estruturantes da trama. $\mathrm{O}$ tópos do deleite e da instrução, presente na Ars Poetica de Horácio, é mobilizado na afirmação de que editor presta grande serviço, pois a obra pode divertir e educar pela verdade dos fatos retratados. O prefácio também mobiliza o tópos da modéstia, que segundo o editor, está associado à seriedade e à aplicação religiosa que motivam o relato. ${ }^{3}$ A mobilização destes lugares-comuns que servem para conquistar a atenção e a benevolência dos leitores parece especialmente útil na apresentação de um enredo que pressupõe a dissimulação para se afirmar verdadeiro.

A recorrência destes temas em Robinson Crusoé repercute a desestruturação do que René Wellek (1987) denomina sistema de crítica neoclássico, modelo baseado na apropriação de preceitos poéticos da antiguidade estruturado nos séculos XVI e XVII. Segundo Wellek (1987), esta desestruturação se deu, em grande medida, devido à ampliação do público leitor e às novas demandas do mercado literário. Se no século XVII o padrão da crítica era o tratado formal, a poética, frequentemente escrita em latim, o século XVIII popularizou o tratado vernacular

Uses to which wise Men always apply them (viz.) to the Instruction of others by this Example, and to justify and honour the Wisdom of Providence in all the Variety of our Circumstances, let them happen how they will. The Editor believes the thing to be a just History of Fact;* neither is there any Appearance of Fiction in it: And however thinks, because all such things are dispatch'd, ${ }^{*}$ that the Improvement of it, as well to the Diversion, as to the Instruction of the Reader, will be the same; and as such, he thinks, without farther Compliment to the World, he does them a great Service in the Publication." (DEFOE, 2007, p. 44).

${ }^{3}$ Em Literatura europeia e Idade Média latina, Ernst Curtius (2013, p. 123) argumenta que o tópos da modéstia é definido por Cícero em De oratore e pressupõe atitude de submissão e humildade por parte do orador. Curtius (2013) comenta ainda ser comum na diplomática a mescla com as "fórmulas de devoção" que, a partir da autoridade da Bíblia, foram combinadas com as formas de auto-humilhação oriundas do Velho Testamento. 
como expressão da tendência ao tratamento mais informal das questões letradas. Este direcionamento da crítica foi materializado na ampliação de periódicos dedicados a temas literários, pois ao longo do século XVIII a literatura deixa de ser assunto exclusivo de círculos fechados para ser debatida no espaço público como matéria cotidiana.

Em "Defoe and Poetic Tradition", J. Paul Hunter (2008) lembra que, como a maioria de seus contemporâneos, Daniel Defoe rendeu homenagens às ideias neoclássicas de classificação e estrutura dos gêneros, mas também, como seus contemporâneos, mobilizou as regras frouxamente. A estrutura narrativa pouco rígida e a linguagem coloquial empregada no romance não coincidem com o padrão dos textos formatados pelos protocolos letrados dos séculos XVI e XVII. O caráter prosaico da trama contrasta com a aparente formalidade de sua apresentação, apesar de requerer filiação às convenções, Robinson Crusoé está situado em novo horizonte de possibilidades narrativas.

O estilo empregado no relato do náufrago faz referência a tipos textuais distintos: diários e anotações pessoais; autobiografias; reflexões sobre a Providência; aventuras maravilhosas; narrativas de navegação, guias de sobrevivência e conduta, entre outros (HUNTER, 2018, p. 8). Segundo Rebecca Bullard (2018, p. 86), o motivo da ilha remete à tendência iniciada por Utopia (1516), de Thomas Morus, e ampliada no século XVII. Obras como New Atlantis (1627), de Francis Bacon, A Description of the Famous Kingdome of Macaria (1641), de Gabriel Plattes, The Isle of Pines (1668), de Henry Neville, além de tratados anônimos como The Government of a Certain Island Antiently call'd Astreada (1693) e The Free State of Noland (1696) ajudaram a difundir a temática explorada na obra de Daniel Defoe.

A ampla circulação desses textos evidencia a voga de transformação das práticas letradas no século XVIII retratada em The Dunciad, de Alexander Pope. O poema, cuja primeira versão data de 1728 , celebra ironicamente a vitória da literatura popular sobre a erudita, mas defende a separação rigorosa entre essas. The Dunciad evidencia que a consolidação do romance como gênero literário se dá no processo de diferenciação entre os tipos letrados considerados tradicionais e as formas mais efêmeras retratadas pelo poeta inglês.

A transformação das práticas letradas pode ser diretamente associada à difusão da alfabetização e ao aumento da publicação de textos 
ficcionais em prosa. ${ }^{4}$ Entre 1700 e 1740 foram publicados em torno de dez obras ficcionais por ano na Inglaterra, mas a partir de 1740 o número de publicações anuais dobra. Na última década do século XVIII, em torno de oitenta romances são publicados anualmente (SPACKS, 2015, p. 4). A curva ascendente pode ser em parte explicada pelo sucesso considerável de livros como Love in Excess (1726), de Eliza Haywood, e Pamela (1740), de Samuel Richardson, além de Robinson Crusoé. O aumento progressivo na publicação de obras marcadamente prosaicas, cuja classificação podia variar entre novel e romance, evidencia a voga do consumo de textos com apelo ficcional.

$\mathrm{Na}$ edição de setembro de 1725 do London Journal, uma carta atribuída a Benjamin Hoadley (apud SEIDEL, K., 2011) analisa o prazer oriundo do contato com histórias inventadas. Para o autor, o deleite tem origem justamente na falta de fundamento na realidade que permite a imersão na ficcionalidade. Segundo Hoadley (apud SEIDEL, K., 2011, p. 5), Robinson Crusoé exemplifica perfeitamente este tipo de literatura cada vez mais popular em Londres devido ao caráter evidentemente fantasioso. O prazer da leitura é associado ao descompromisso com a veracidade, e o autor considera a falta de notícias relevantes como principal incentivo para o consumo de leituras de invenção. A ficção despretensiosa lida cotidianamente distrai à medida que assume função complementar ao noticiário.

O depoimento de Benjamin Hoadley (apud SEIDEL, K., 2011) sinaliza como as novas formas literárias redimensionam o problema da representação. A narrativa, atraente por ser deliberadamente falsa, traduz a referencialidade em termos de verdade e mentira. A expectativa em torno da verossimilhança inicialmente se apresenta como um problema de fidedignidade da narrativa, mas, no caso de Robinson Crusoé, a conjunção da autoria dissimulada com narração autoral amparada no registro documental fictício produz uma dobra ficcional estratégica para a definição deste regime de funcionamento dos textos forjado a partir do século XVIII.

A recepção da obra de Daniel Defoe mostra como os significados da escrita ficcional e da autoria literária, desdobrada no problema do

\footnotetext{
${ }^{4}$ Segundo James Van Horn Melton (2004, p. 82), estima-se um salto no letramento masculino na Inglaterra de trinta por cento em 1640 para mais de sessenta por cento em meados do século XVIII. No mesmo período o percentual de mulheres alfabetizadas girava em torno de quarenta por cento.
} 
nome, movimentaram os debates acerca das características e funções do romance. Revela ainda como as práticas letradas foram redefinidas à luz da compreensão da representação como efeito da autoria e da criação do direito autoral. A maquinaria crítica que pessoaliza a invenção poética ajudou a inventar os códigos da ficção naquela que Samuel Johnson (apud MELTON, 2004, p. 123) definiu como "a era dos autores".

A relação entre nome e autoria é o tema central da mais severa e conhecida crítica que Robinson Crusoé recebeu no século XVIII. Em The Life and Strange Surprizing Adventures of Mr. D—De F-, também publicado em 1719, Charles Gildon repercute o sucesso editorial do livro Daniel Defoe. O panfleto, organizado em duas seções, denuncia a trama como mera alegoria da vida problemática do autor. Na primeira seção, o diálogo fictício entre Defoe e Crusoé apresenta uma discussão na qual o personagem questiona a inconsistência de sua personalidade. Defoe defende-se enfatizando Crusoé como sua criação favorita, construída à sua imagem e semelhança. Em outro trecho do diálogo, Defoe confessa escrever prioritariamente por dinheiro, por isso trabalhou tanto para Whigs quanto para Tories, partidos adversários na política inglesa (RODGERS, 1995, p. 42).

Charles Gildon não foi o primeiro a questionar a moralidade da atuação pública de Daniel Defoe, que foi alvo de questionamentos desse tipo não só durante sua vida profissional, mas também após sua morte, como mostra Maximilian Novak (2018). A particularidade do panfleto em questão é a transformação das acusações morais em argumento de crítica literária. Para Charles Gildon (1719), a desonestidade não se expressa apenas pelo oportunismo comercial do escritor, mas pela representação indevida das matérias religiosas e das doutrinas cristãs. O tratamento informal dos desígnios da Providência, constantemente evocados para caracterizar o destino do personagem principal, desqualificariam a obra pois, segundo os parâmetros do crítico, a sacralidade de temas elevados não seria condizente com "ficções e mentiras" (GILDON, 1719, p. 47).

Para uma parte da crítica inglesa da primeira metade do século XVIII, o tratamento das verdades religiosas pelas mentiras da ficção indicaria o declínio da religiosidade. O uso vulgar das doutrinas, a relação irônica que Robinson Crusoé estabelece com seu destino, seriam marcas da secularização a ser combatida por letrados como Charles Gildon (1719), para quem a obra de Defoe, ao mentir sobre sua origem, falsearia a experiência cristã. No cenário no qual a ficção passa a mobilizar 
temas elevados, os limites entre a mentira e a verdade precisavam ser controlados na justa hierarquia dos textos.

Os comentários de Charles Gildon evidenciam como, em meio aos debates acerca da universalidade da experiência estética, o problema da representação articula-se aos termos da verdade literária. Na epístola que conclui a análise da obra de Defoe, Gildon (1719) afirma não ser contra escritores e fábulas, dada a antiguidade desse tipo de escrita, mas denuncia Robinson Crusoé pela falta de interesse público. Destaca que a história do naufrágio desencoraja a navegação, pois os eventos inverossímeis deturpariam uma das mais valorosas e lucrativas atividades humanas (GILDON, 1719, p. 25).

Gildon (1719) enfatiza que as mentiras apresentadas podem ter efeitos práticos perversos e por isso, a dissimulação da autoria, a farsa do prefácio, a zombaria da Providência, a inconsistência dos personagens e, por fim, a inverossimilhança dos eventos narrados fariam da publicação ato indecoroso. The Life and Strange Surprizing Adventures of $\mathrm{Mr}$ $D$ - De F- exemplifica como o problema da autoria faz referência às responsabilidades atribuídas aos textos impressos e como o nome próprio passa a responder pelos desvios das funções autorais, pois o paradigma da honestidade é evocado dado o suposto uso inadequado dos códigos da invenção poética.

No prefácio de The Farther Adventures of Robinson Crusoe o editor atribui o sucesso da obra anterior à variedade de temas abordados e à forma agradável da exposição, mas também rebate algumas acusações:

Todos os esforços de pessoas invejosas para censurá-lo por ser um romance, para procurar por erros geográficos, inconsistências no relato e contradições factuais, mostraram-se falhos e tão impotentes quanto maliciosos. A referência justa a cada incidente, as inferências religiosas e úteis extraídas de cada parte, são testemunhos do bom desígnio de torná-lo público, e deve legitimar toda a parte que possa ser chamada de invenção ou parábola na história. (DEFOE, 2004, p. 4, tradução nossa). ${ }^{5}$

\footnotetext{
${ }^{5}$ No original: "All the Endeavours of envious People to reproach it with being a Romance, to search it for Errors in Geography, Inconsistency in the Relation, and Contradictions in the Fact, have proved abortive, and as impotent as malicious. The just Application of every Incident, the religious and useful Inferences drawn from every Part, are so many Testimonies to the good Design of making it publick, and must legitimate all the Part that may be call'd Invention, or Parable in the Story."
} 
A defesa argumenta que o valor do livro reside na sua utilidade religiosa e prática. Segundo o editor, a invenção e o recurso da parábola devem ser considerados legítimos por estarem a serviço de uma trama bem construída. A alegação sustenta que a invenção obedece a um propósito maior, o bem público, mas repercute a desconfiança da crítica inglesa em relação à natureza do discurso ficcional, pois questiona a classificação de Robinson Crusoé como romance.

Em The Progress of Romance, publicado em 1785, Clara Reeve examina os tipos textuais em voga e estabelece a diferença entre os gêneros novel e romance. Para Reeve (apud NIXON, 2009, p. 350), o primeiro surge das ruínas do segundo, mas "ancient romance" e "modern novel" seriam tipos distintos de escrita. A diferenciação, que se tornou referência nos estudos literários, atribui ao romance o uso de linguagem elevada para descrever eventos improváveis ou impossíveis, enquanto define novel como gênero voltado para coisas familiares, cotidianas, representadas com linguagem coloquial. Segundo a autora, esse último cativaria os leitores pela capacidade de representar a realidade com naturalidade e fazer com que as narrativas "pareçam tão prováveis a ponto de nos fazer pensar (ao menos enquanto estamos lendo) que tudo é real, até que sejamos afetados pelas alegrias e angústias das pessoas na história, como se fossem nossas" (REEVE apud NIXON, 2009, p. 352, tradução nossa). ${ }^{6} \mathrm{~A}$ argumentação de Clara Reeve confirma a tendência da crítica setecentista ao privilégio da prosa afeita a eventos críveis e ajuda a explicar porque o prefácio de The Farther Adventures of Robinson Crusoe nega a rotulação que o classifica como romance.

A proposta da dissimulação indica que o sentido da verdade de Robinson Crusoé depende, em grande medida, da suposta origem do relato, ou seja, é suportada pela maquinaria dos elementos pré-textuais. $\mathrm{O}$ universo ficcional é construído com auxílio dos aparatos que contrastam

\footnotetext{
${ }^{6}$ No original: "The Novel gives a familiar relation of such things, as pass every day before our eyes, such as may happen to our friend, or to ourselves; and the perfection of it, is to represent every scene, in so easy and natural a manner, and to make them appear so probable, as to deceive us into a persuasion (at least while we are reading) that all is real, until we are affected by the joys or distresses, of the persons in the story, as if they were our own appear so probable, as to deceive us into thinking (at least while we are reading) that all is real, until we are affected by the joys and distresses, of the persons in the story, as if they were our own."
} 
níveis ficcionais distintos: o gesto que começa com a assinatura dos livros, se estende na ficção de autor e continua na invenção editorial do prefácio.

O mesmo prefácio denuncia a publicação de versões clandestinas e reduzidas da obra evidenciando as tensões que marcam o processo de reorganização das práticas letradas. $\mathrm{O}$ comentário demonstra como as questões sobre originalidade e propriedade autoral dos textos assumem novos papéis na cena literária.

O prejuízo que esses homens causam ao proprietário desta obra é uma prática que todos os homens honestos abominam; e ele acredita que pode desafiá-los a mostrar a diferença entre isso e roubar na estrada, ou arrombar uma casa. Se eles não puderem demonstrar qualquer diferença no crime, vão achar difícil mostrar porque deveria haver qualquer diferença no castigo: e ele responderá por isso, pois nada faltará de sua parte, para lhes fazer justiça. (DEFOE, 2004, p. 5, tradução nossa). ${ }^{7}$

O debate sobre a criação de legislação específica para regular as práticas letradas perpassa todo o século XVIII e, em texto publicado no periódico The Review, em fevereiro de 1710, Daniel Defoe expõe seus argumentos em defesa da propriedade autoral recorrendo à metáfora do livro como filho dos escritores, produto da invenção criativa. $\mathrm{O}$ texto exemplifica o tom do debate público em torno da legislação que garantiria a negociação dos direitos autorais entre autores e livreiros. ${ }^{8}$

\footnotetext{
${ }^{7}$ No original: "The Injury these Men do the Proprietor of this Work, is a Practice all honest Men abhor; and he believes he may challenge them to shew the Difference between that and Robbing on the Highway, or Breaking open a House. If they can't shew any Difference in the Crime, they will find it hard to shew why there should be any Difference in the Punishment: And he will answer for it, that nothing shall be wanting on his Part, to do them Justice."

8 "The Statute of Anne", considerada a primeira lei moderna de direitos autorais, foi aprovado em 1710 e aumentou a importância dos escritores no mercado editorial. Antes da promulgação do estatuto, o mercado era regulado pela Lei de Licenciamento da Imprensa de 1662 que garantia à associação de impressores, The Stationers' Company, o monopólio da impressão e censura de obras literárias. "The Statute of Anne" limitou o uso dos direitos autorais por período de catorze anos para livros publicados após 1710, mas permitia a renovação enquanto o autor ainda estivesse vivo. Para os livros impressos anteriormente a lei garantia a exploração dos direitos pelo período de vinte e um anos (MELTON, 2004, p. 138).
} 
Segundo Dustin Griffin (2005), as bases da noção moderna de autoria literária foram lançadas naquele cenário de regramento jurídico e comercial entre o final do século XVII e início do século XVIII. O fenômeno pode ser percebido pela identificação generalizada da autoria nas páginas de títulos dos livros; pela profissionalização do autor; pela consolidação da venda de livros como empreitada comercial; pelo crescimento do mercado editorial e pelo aumento na publicação de periódicos voltados à crítica e pelo desenvolvimento do jornalismo político. Essas condições - que não garantiram estabilidade financeira para escritores no primeiro momento - expuseram as tensões entre conviçcões artístico-literárias e as demandas do mercado. Interesses de editores, vendedores de livros e leitores se tornaram decisivos nas projeções das ambições autorais.

O caso de Daniel Defoe exemplifica o processo de profissionalização dos ofícios letrados no contexto em que a libertação dos domínios da Stationers' Company ajudou a definir os termos da propriedade literária, e, consequentemente, as funções autorais. Se a teoria neoclássica tendia a reafirmar a condição do escritor como a do artesão que moldava suas obras de acordo com preceitos retórico-poéticos estabelecidos pelas práticas do passado, a nova situação autoral abre espaço para a criação como originalidade autorreferente. A conjuntura de personificação da criatividade, na qual a invenção literária é deslocada do âmbito da tradição, é também o cenário de ampliação das responsabilidades.

O prefácio de Serious Reflections During the Life and Surprising Adventures of Robinson Crusoe nega novamente o caráter meramente fictício das obras anteriores, mas agora é o próprio Robinson Crusoé, e não mais o editor, que assina o texto para rebater as acusações de que as duas obras anteriores seriam meros romances.

Eu, Robinson Crusoé, estando neste momento em sã consciência e memória, Graças a Deus, declaro por meio deste que as objeções deles são invenções escandalosas em propósito e factualmente falsas; e afirmo que a história, embora alegórica, também é histórica; e que é a bela representação de uma vida de infortúnios sem precedentes e de uma variedade que não se encontra no mundo, sinceramente adaptada e destinada ao bem comum da humanidade, e concebida a princípio, como agora está agora 
largamente utilizado, para os usos mais sérios possíveis. (DEFOE, 1720 , p. 2 , tradução nossa). ${ }^{9}$

A elevação do tom reafirma o compromisso do narrador com a verdade. As reflexões morais do terceiro volume devem iluminar a missão nobre e o caráter público de todo o legado de Robinson Crusoé, testemunho vivo das aventuras, que evoca a honra pessoal para legitimar os relatos. O terceiro prefácio sustenta a verdade superior que motiva a empreitada narrativa pois, mais importante que os fatos narrados, são as lições verdadeiras que dele podem ser inferidas.

A referência à verdade histórica, comum nas descrições de romances no século XVIII, era frequentemente utilizada para caracterizar narrativas pretensamente reais como em The History and Remarkable Life of the Truly Honourable Colonel Jacque, Commonly Called Colonel Jack (1722), do próprio Daniel Defoe. No caso de Serious Reflections During the Life and Surprising Adventures of Robinson Crusoe, a referência histórica faz alusão à factualidade metafórica à proporção que o alegórico sinaliza para a artificialidade literária. História e alegoria são complementos forjados mutualmente, indissociáveis como a forma e o conteúdo. Na assinatura de Crusoé, a tentativa de controle do significado pressupõe a imposição do alcance do texto e sua importância para o desenvolvimento moral dos leitores. Transformado em ativo da trama, o significado da obra sugere origem histórico-alegórica.

Analisadas em conjunto, as classificações indicadas nos três prefácios variam em torno de premissas básicas de sentido. $\mathrm{O}$ primeiro, assinado pelo editor, apresenta a trama como história real sem qualquer artifício ficcional; o segundo, também assinado pelo editor, sugere a possibilidade de algumas partes serem consideradas invenções ou parábolas; e no terceiro, o protagonista assume a defesa das obras tratando sua aventura como história imaginada. O relato, inicialmente apresentado

\footnotetext{
${ }^{9}$ No original: "I Robinson Crusoe being at this Time in perfect and sound Mind and Memory, Thanks be to God therefore do hereby declare, their Objection is an Invention scandalous in Design, and false in Fact; and do affirm, that the Story, though Allegorical, is also Historical; and that it is the beautiful Representation of a Life of unexampled Misfortunes, and of a Variety not to be met with in the World, sincerely adapted to, and intended for the common Good of Mankind, and designed at first, as it is now farther apply'd, to the most serious Uses possible."
} 
como factual, é gradualmente transformado em tipo textual híbrido, ao mesmo tempo verdadeiro e ficcional.

Persistem as afirmações de elementos verídicos, da honra do autor, do caráter moralmente elevado e do benefício público das obras, mas os prefácios sugerem que, em última instância, a verdade se sobrepõe aos elementos da intriga. A razão moral é argumento central e a verossimilhança importa como condição para a empatia. Os momentos de distração ou instrução ética que o leitor pode obter independem da realidade dos eventos narrados. Verdade e ficção figuram apenas como instrumentos para que o texto cumpra suas funções, amparado, em alguma medida, nos efeitos retóricos do lugar-comum que associa deleite e instrução, redefinido pela crítica do século XVIII.

No famoso prefácio de The Plays of William Shakespeare (1725), Samuel Johnson (apud RALEIGH, 1908, p. 56) argumenta que a literatura deve ser a representação justa de coisas e eventos efetivamente existentes tomando como base as ações realmente praticadas. Suas suspeitas em relação à ficção e à defesa contundente da expressão da verdade ajudaram a compor o arsenal crítico que colocaria o discurso ficcional em constante suspeição. Nesse cenário, argumentos morais foram frequentemente mobilizados para justificar a quebra de determinados princípios poéticos referidos aos termos da verossimilhança. As relações entre ficção, invenção, mentira, moralidade e verdade, debatidas no cotidiano da crítica literária, ajudaram a definir as fronteiras da narração sustentadas pelo motivo do bem público, da razão superior.

Os supostos objetivos morais das aventuras de Robinson Crusoé indicam o deslocamento das modalidades de representação. A perspectiva neoclássica da imitação, da reprodução da realidade mediada pela tradição, assume nuances singulares tendo em vista a moralidade autoral. A verdade de Robinson Crusoé faz referência à condição universal natural, mas a partir de decoro próprio. A empreitada representativa que as três obras encerram sugere a flexibilização das normativas de acesso ao real, e as dissimulações das assinaturas e das tramas referendam a criação poética como tipo particular de invenção. O valor do que é representado não está mais nos temas elevados, mas nos desdobramentos das funções do texto. Assim, a ficção de autor, desdobrada no problema da criação literária, se sobrepõe ao objeto da representação.

Ainda no prefácio de Serious Reflections During the Life and Surprising Adventures of Robinson Crusoe - após elencar alguns dos 
eventos verdadeiros narrados nos livros anteriores, como a história do urso na árvore e a luta contra lobos na neve -, o narrador admite que as aventuras de Robinson Crusoé refletem situações dramáticas de sua vida, os altos e baixos da fortuna e seus naufrágios pessoais que, por vezes, se deram mais em terra que no mar. $\mathrm{O}$ texto sugere que a originalidade da biografia do narrador não está nos eventos extraordinários que marcaram sua vida, mas na força alegórica de seus infortúnios.

O relato do meu susto com algo na minha cama, foi palavra por palavra, a história do que aconteceu, e na verdade todas essas coisas receberam muito pouca alteração, exceto o necessariamente requerido para a remoção da cena de um lugar para outro. [...] Além disso, este é o bom e justo desígnio de toda parábola ou história alegórica levada a efeito, a melhoria moral e religiosa. (DEFOE, 1720 , p. 5 , tradução nossa). ${ }^{10}$

As definições de parábola e alegoria, mobilizadas como argumento de defesa e referidas ao uso evasivo da referencialidade histórica, servem à tentativa de controle do significado do texto e ao esforço de classificação da narrativa. $\mathrm{O}$ aprimoramento moral religioso como parâmetro de sentido sustenta o conjunto das histórias, cria artificialmente o escopo de atuação do texto. A imparcialidade dos leitores é solicitada de modo a evitar a confrontação direta entre verdade e mentira, da qual Robinson Crusoé busca dramaticamente manter distância. Assim, a metáfora da ilha aplica-se ao isolamento da narração factual e fictícia.

A premissa do ensinamento moral serve tanto para a defesa do argumento principal quanto para explicar a forma particular do relato, uma vez que o narrador afirma ter recusado os modelos narrativos tradicionais. Os eventos inusitados do enredo são tratados como parte da estratégia de persuasão, pois, de acordo com o narrador, o público não teria interesse em uma trama na qual pudesse se identificar plenamente.

O prefácio, que ratifica o compromisso de Robinson Crusoé com uma nova forma de escrita, é uma declaração pública a favor do tratamento de temas elevados em formas coloquiais de escrita. Segundo seu autor,

\footnotetext{
${ }^{10}$ No Original: "The Story of my Fright with something on my Bed, was Word for Word a History of what happened, and indeed all those Things received very little Alteration, except what necessarily attends removing the Scene from one Place to another. [...] Besides all this, here is the just and only good End of all Parable or Allegorick History brought to pass, viz. for moral and religious Improvement."
} 
esse tipo de texto terá lugar no futuro, quando os mais jovens se rebelarão contra seus pais e a natureza ordinária de um livro não deverá impedir a propagação da mensagem (DEFOE, 1720). Para Robinson Crusoé, a valorização das reflexões do homem comum pressupõe rompimento com a tradição e a flexibilização de paradigmas, mas apesar das dúvidas quanto ao reconhecimento contemporâneo da obra, o narrador confia que no futuro os leitores serão menos preconceituosos e perceberão o valor das reflexões apresentadas no livro (DEFOE, 1720, p. 7).

Mesmo que a história da recepção indique que a repercussão de Robinson Crusoé não se deveu à relevância das reflexões morais, vide o quase esquecimento de Serious Reflections During the Life and Surprising Adventures of Robinson Crusoe, a defesa da abordagem prosaica de temas elevados faz da obra de Daniel Defoe marco no processo de formação histórica da representação realista e, como consequência, do romance. Em Lectures on Rhetoric and Belles Lettres, obra de 1783, Hugh Blair (2010) considera a ficção francesa superior à inglesa, porém destaca The Adventures of Robinson Crusoe como a maior obra ficcional já escrita. Segundo Blair (2010), em nenhum outro idioma haveria trama tão bem estruturada, capaz de cativar a imaginação dos leitores pela aparência simples e verdadeira. A verossimilhança sedutora da obra de Defoe teria ainda o mérito da utilidade, pois mostraria o quanto as forças naturais do homem podem agir positivamente em momentos de dificuldade.

Nos três séculos de comentários sobre a obra de Daniel Defoe, o aspecto prosaico da narração foi recorrentemente destacado. No entanto, é preciso considerar como o suposto pioneirismo realista foi articulado ao conjunto de estratégias persuasivas centradas no registro autoral, pois a impressão de realidade dos textos parece diretamente articulada aos efeitos produzidos pela dissimulação.

Segundo James Van Horn Melton (2004, p. 99), o romance epistolar se tornou uma das mais populares formas literárias do século XVIII justamente por criar a ilusão de conexão verossímil entre o mundo privado e a esfera pública. Obras como Cartas persas, de Montesquieu; Clarissa, de Richardson; La Nouvelle Hélö̈se, de Rousseau; Os sofrimentos do jovem Werther, de Goethe; e Ligações perigosas, de Laclos ilustram a voga cujo auge seria atingido na segunda metade do século. Ainda segundo Melton (2004), esses textos criavam a impressão de autenticidade, pois os autores alegavam ter recebido, ou simplesmente descoberto, as cartas transformadas em romance. A autoria dissimulada 
ajudava a eliminar as barreiras entre escritores e leitores, além de atenuar as críticas que recaíam sob a ficção como narrativa mentirosa.

A assinatura de Robinson Crusoé, além de certificar a autoria dos diários integralmente entregue ao público como elemento interno da obra, intensifica o efeito da ficção de autor, pois a autoria é dissimulada na artificialidade do diário e na figura do narrador fictício que assina o livro. Kevin Seidel (2011) argumenta que a crítica em geral se apressa em analisar os prefácios como vindos da voz de Daniel Defoe, e sugere que as obras sejam lidas a partir, e não após o prefácio. Mas, de acordo com o exposto até aqui, talvez seja possível propor que essas sejam lidas a partir da capa, ou da folha de rosto do livro.

Segundo Michael Seidel (2008), o núcleo da teoria da ficção de Daniel Defoe está na crença de que a mente só se expande a ponto de cativar o leitor se a trama respeitar os parâmetros das leis naturais, se os eventos imaginados não ignorarem o funcionamento básico da realidade. Ainda segundo Seidel (2008), Defoe reafirmou esse argumento várias vezes e se sentiu particularmente pressionado a fazê-lo diante das acusações contra Robinson Crusoé. Analisadas em conjunto, as três obras configuram a tomada de posição em defesa do discurso ficcional moldada no debate público. Daniel Defoe responde às acusações de falsidade para reafirmar a veracidade do personagem que criou pela mobilização dos conceitos de verdade histórica e alegoria. Em grande medida, a originalidade editorial é estabelecida na relação indissociável entre verdade e ficção criada pelas estratégias de apresentação da narrativa.

Considerado o processo de transformação dos paradigmas letrados do século XVIII, é possível notar que, no caso de Robinson Crusoé, os artifícios da dissimulação autoral pressupõem o uso de lugares comuns, como os tópos da modéstia e da instrução, para enunciar gesto de desinteresse pessoal e reconfigurar os termos da representação. A dissimulação expressa, portanto, a tentativa de criar espaço nas brechas da polarização entre a mentira e a verdade.

Ao associar veracidade e verossimilhança, a assinatura de Robinson Crusoé, enfatizada na impressão do prefácio da terceira obra, ratifica a ficção da referência histórica como registro alegórico. Assim, a escrita evoca a imaginação como meio legítimo de acesso à realidade situada entre o registro alegórico e o histórico. A narrativa ficcional pleiteia o espaço aberto pelo afrouxamento da hierarquia clássica entre a realidade e sua representação poética. 
No contexto de redefinição das preceptivas retórico-poéticas, as ficções que compõem o universo de Robinson Crusoé expressam a desobrigação estética e jurídica que solicita, além da representação sem o compromisso com a verdade, o resguardo quanto às responsabilidades autorais. No conjunto das aventuras, a narração avança na possibilidade de controle do sentido desdobrada nas invenções editoriais e na defesa da natureza edificante do texto. Assim, o engenho narrativo composto de elementos que emolduram a trama serve também como argumento para a flexibilização da hierarquia da representação quando a composição poética deixava de se referir à autoridade da tradição para ser parte de um outro sistema referendado na autoria como fundamento da autonomia do discurso ficcional.

\section{Referências}

BAPTISTA, Abel Barros. Autobibliografias: solicitação do livro na ficção de Machado de Assis. Lisboa: Relógio D’água, 1998.

BLAIR, Hugh. Lectures on Rhetoric and Belles Lettres. London: Gale ECCO, 2010. v. II.

BULLARD, Rebecca. Politics, History, and the Robinson Crusoe Story. In: RICHETTI, John (ed.). The Cambridge Companion to "Robinson Crusoe”. New York: Cambridge University Press, 2018. p. 84-98. DOI: https://doi.org/10.1017/9781107338586.007.

BUNIA, Remigius. Uma história moral da ficção. In: GALLE, Helmut P. E.; PEREZ, Juliana P.; PEREIRA, Valéria S. (org.). Ficcionalidade: uma prática cultural e seus contextos. São Paulo: FFLCH, 2018. p. 95-109.

CURTIUS, Ernst Robert. Literatura europeia e Idade Média latina. Tradução de Teodoro Cabral e Paulo Rónai. São Paulo: Editora da Universidade de São Paulo, 2013.

DEFOE, Daniel. Robinson Crusoe. New York: Oxford University Press, 2007. DOI: https://doi.org/10.1093/owc/9780199553976.001.0001.

DEFOE, Daniel. Robinson Crusoé. Tradução de Sergio Flaksman. São Paulo: Penguin Classics Companhia das Letras, 2011. 
DEFOE, Daniel. Serious Reflections During the Life and Surprising Adventures of Robinson Crusoe: With his Vision of the Angelick World. London: W. Taylor, 1720.

DEFOE, Daniel. The Farther Adventures of Robinson Crusoe. Maryland: Wildside Press, 2004.

DEFOE, Daniel. The Review, v. VI, n. 129, 2 Feb. 1710.

GENETTE, Gérard. Paratextos editoriais. Tradução de Álvaro Faleiros. Cotia: Ateliê Editorial, 2009.

GILDON, Charles. The Life and Strange Surprizing Adventures of Mr $D-D e F-$. London: J. Roberts, 1719.

GRIFFIN, Dustin. The social World of Authorship 1660-1714. In: RICHETTI, John (ed.). The Cambridge History of English Literature, 1660-1780. Cambridge: Cambridge University Press, 2005. p. 37-60. DOI: https://doi.org/10.1017/CHOL9780521781442.004.

HUNTER, J. Paul. Defoe and Poetic Tradition. In: RICHETTI, John (ed.). The Cambridge Companion to Daniel Defoe. New York: Cambridge University Press, 2008. p. 216-230. DOI: https://doi.org/10.1017/ CCOL9780521858403.013.

HUNTER, J. Paul. Genre, Nature, Robinson Crusoe. In: RICHETTI, John (ed.). The Cambridge Companion to "Robinson Crusoe". New York: Cambridge University Press, 2018. p. 3-15. DOI: https://doi. org/10.1017/9781107338586.002.

KELNER, Thomas. Robinson Crusoe: Daniel Defoe. Edição e introdução de Thomas Keymer. Notas de Thomas Keymer e James Kelly. New York: Oxford University Press, 2007.

KONRAD, Eva-Maria. "The Poet, He Nothing Affirms, and Therefore Never Lieth"? An Analysis of Editorial Fiction. DIEGESIS, Wuppertal, v. 4, n. 1, p. 1-17, 2015.

MELTON, James Van Horn. The Rise of the Public in Enlightenment Europe. Cambridge: Cambridge University Press, 2004.

NIXON, Cheryl L. (ed.). Novel Definitions: An Anthology of Commentary on the Novel, 1688-1815. Peterborough: Broadview Press, 2009. 
NOVAK, Maximilian E. The Deplorable Daniel Defoe: His Supposed Ignorance, Immorality, and Lack of Conscious Artistry. Digital Defoe: Studies in Defoe \& His Contemporaries, [S. l.], n. 10.1, p. 1-17, fall 2018.

RALEIGH, Walter. Johnson on Shakespeare. London: Oxford University Press, 1908.

RODGERS, Pat (ed.). Daniel Defoe: The Critical Heritage. London: Routledge, 1995.

SEIDEL, Kevin. Robinson Crusoe as Defoe's Theory of Fiction. Novel: A Forum on Fiction, North Carolina, v. 44, n. 2, p. 165-185, summer 2011. DOI: https://doi.org/10.1215/00295132-1260941.

SEIDEL, Michael. Robinson Crusoe: Varieties of Fictional Experience. In: RICHETTI, John (ed.). The Cambridge Companion to Daniel Defoe. New York: Cambridge University Press, 2008. p. 182-199. DOI: https:// doi.org/10.1017/CCOL9780521858403.011.

SPACKS, Patricia Meyer. The 1740s. In: ARATA, Stephen; HALEY, Madigan; HUNTER, J. Paul; WICKE, Jennifer (ed.). A Companion to English Novel. Oxford: Wiley-Blackwell, 2015. p. 3-17. DOI: https://doi. org/10.1002/9781118607251.ch1.

WATT, Ian. A ascensão do romance. Tradução de Hildegard Feist. São Paulo: Companhia das Letras, 2010.

WELLEK, René. História da crítica moderna. Tradução de Lívio Xavier. São Paulo: Editora Herder, 1967.

WOLF, Werner. Is Aesthetic Illusion >illusion référentielle ? >Immersion in (Narrative) Representations and Its Relationship to Fictionality and Factuality. Journal of Literary Theory, [S.l.], v. 2, n. 1, p. 99-126, 2008. DOI: https://doi.org/10.1515/JLT.2008.007. 